\title{
LA NAVIDAD: MEMORIAS DE UN NAUFRAGIO DE VELOZ MAGGIOLO
}

\section{About Christmas: memories of a shipwreck of Veloz Maggiolo}

\author{
Fari Rosario ${ }^{1}$
}

\section{Reseña de libro}

Acabo de leer la novela La Navidad: memorias de un naufragio (2016), el texto más reciente del novelista mayor de República Dominicana: Marcio Veloz Maggiolo. El texto de 263 páginas fue publicado por Lacre Ediciones del Grupo Editorial Áltera, en Madrid, España, como parte de la colección que lleva por título "Maestros de la Novela Histórica”. La publicación confirma que el novelista no desmaya en su labor y que sigue explorando los frescos senderos de la imaginación y su obsesión por el tema de la memoria histórica y la realidad socio-cultural desde múltiples perspectivas. Este texto aborda, con destreza y maestría, las vicisitudes surgidas años después del primer viaje del almirante Cristóbal Colón; describe, pues, una realidad histórica que marca de modo profundo la historia de Occidente. El narrador esculpe nuevas imágenes del mundo que creemos conocer al dedillo. El novelista muestra que es un hombre con vasta cultura, con dominio del discurso histórico y con sentido de la intuición; confirma aquí su búsqueda sin término en el ámbito de la literatura y el arte de la novelística. Con esto ensancha una dilatada trayectoria literaria, con varios libros de cuentos, varios ensayos y con más

1.ProfesordelInstitutoTecnológicodeSantoDomingo(INTEC), República Dominicana. ramon.rosario@intec.edu.do de dieciocho novelas: dos de ellas editadas por la editorial Siruela, en España.

Veloz Maggiolo comenzó su novelística escribiendo textos alegóricos y simbólicos. Es, sin lugar a dudas, uno de los iniciadores del ciclo de la novela bíblica en nuestro país, según lo afirmado por Fornerín (2017) y Di Pietro (2010), entre otros estudiosos del discurso literario dominicano. Lo paradójico es que en la década de los ochenta, Marcio dio un importante giro a su producción novelística, ya que asume un discurso narrativo - muy propio de élla impronta la poética de lo real maravilloso cuyos primeros referentes son los mitos fundacionales del Caribe. Con su novela La biografía difusa de Sombra Castañeda (1981) comienza este ciclo.

La Navidad: memorias de un naufragio, no solo sorprende por su título, con su matiz anglosajón (a lo Dickens), sino que además -con este texto- el escritor incursiona en la nueva novela histórica. Un género fundado en América Latina por Alejo Carpentier y que resulta muy relevante para la lectura esencial de los discursos latinoamericanos y sus encrucijadas, ya que, según Menton (1973), la nueva novela histórica tiende a la fragmentación de la historia y a su desmitificación de los discursos oficiales.

La novela se desarrolla durante los ańos posteriores al descubrimiento de América, hecho ocurrido en 
1492. La acción que guía la diégesis es la extensa confesión de fray Nathaniel (un hombre concupiscente y avaro) y que tiene como destinatario final a fray Tomás de Abril, su confesor, y uno de los miembros poderosos de la orden religiosa de los Jerónimos. Él busca con ansiedad la aprobación y el auspicio de la Orden religiosa para emprender su nueva aventura: regresar a La Española, no tanto para recuperar a su mujer, una india llamada Jariquena, sino porque le interesa encontrar los rescates escondidos por los hombres de Cristóbal Colón, durante el primer viaje a la Isla:

Mi querido y sabio amigo fray Tomás, se dice por estos predios del Guadalquivir que se escriben libros varios sobre el Almirante y quizás estos datos pobres pero ciertos que pondré en vuestras manos, nos permitan volver a La Española, como es mi deseo de años, para conseguir, tal y como os he propuesto, identificar el lugar donde el aguacil y capitán Diego de Arana guardó para sí los rescates que el Almirante nos encomendó cuidar, cuando se despidiera pensando retornar después de su primer viaje. Hoy, luego de tanta vida desorganizada pero no falta de razones, puedo afirmaros sin miedo que soy uno de los sobrevivientes del Fuerte de La Navidad. Agradezco vuestra bonhomía, porque aun dudándolo, me habéis conseguido estancia en este monasterio jerónimo donde creo que os podré dar nuevas razones de mi viaje y aventuras en Las Indias. (2016, p. 11)

El hecho es que al llegar a tierra firme, Colón funda la Isabela, en Puerto Plata, en la costa norte de la Isla; lo hace con la ayuda de los indígenas, pues ya tenía pocas provisiones y, además, la mayoría de sus marineros estaban enfermos y desnutridos. Así comienza la explotación y la irreversible confrontación entre los nativos y los marineros comerciantes y foráneos.

El personaje-narrador, fray Nathaniel, es -en realidad- sobrino de Josef Ben Hailevi Haiviri, también conocido como Luis de Torres - un judío que dominaba varias lenguas y que Colón invitó para que lo acompañara en su primer viaje-, dado que tenía facilidad para hablar y entender las lenguas orientales. Al marcharse en el segundo viaje, Colón los deja en la isla descubierta, pues quiere que ambos aprendan las lenguas de la región. El error del Almirante fue pensar que todos los indios eran iguales y que, por tanto, todos hablaban una misma lengua, lo cual no era cierto. El narrador testigo de los hechos subraya en varias ocasiones que, en la isla descubierta, había cuatro lenguas: la lengua ciguaya, la lengua macorije, la lengua taína (la más conocida) y la lengua de los nuhuirey (2016, p. 77). Tal parece que los aguerridos indios caribes o canibas hablaban en ciguayo.

El problema comenzó con los abusos cometidos por Diego de Arana contra los indígenas indefensos y siempre dispuestos a trabajar. El narrador reconoce que a este capitán "se le fueron los humos a la cabeza y decapitó indios, y cortó orejas y violentó damiselas en el tiempo que transcurrió desde la partida del Almirante hasta casi el regreso de su segundo viaje" (2016, p. 134). Los indios se hartaron de los atropellos y la continua fustigación, por lo que un grupo de ellos encabezados por Caonabo aprovechó las debilidades e incendiaron la fortaleza La Navidad, asesinando a sus integrantes en diciembre de 1493. Paradójicamente solo sobrevivieron tres personas: Casilda, Luis de Torres y Nathaniel. El cacique de Marién -al ver la gentileza que este último ha tenido con la india Jariquena-, decide perdonarle la vida, pero el aguerrido Caonabo entra en cólera y con furioso gesto le corta la mitad de la lengua para que este no cuente a nadie lo sucedido. Ignoraba que existía algo llamado escritura. Nathaniel se disfraza de indio y adquiere sus gestos y hábitos pues temía que Colón, al regresar de su segundo viaje, lo hiciera cómplice de la matanza de su gente en la fortaleza.

De salto en salto, como la rana toa, el personaje-narrador va contando diversas y variopintas escenas 
que ponen en evidencia la avaricia del proyecto de colonización; así como el choque político-cultural entre los dominadores y los dominados y sobre todo las grandes contradicciones entre el proyecto de Colón quien "tuvo que cambiar la Biblia por la espada” (2013, p. 123). El Almirante no solo tuvo conflicto con los nativos, sino también entre los miembros de su cofradía y los representantes de la Corona. En realidad, el proyecto de la evangelización de las órdenes religiosas limitaba sus propósitos y su ambición, por lo que se opuso al bautizo masivo de los indios, debido a que una vez eran bautizados, no podía tomarlos como esclavos.

En su periplo de vivencias como sobreviviente, Nathaniel no solo narra sus momentos de pasión con Jariquena, sino cómo fue asimilando la cosmogonía de los indios, el ritual de la inhalación de la cojoba, el uso del casabe como alimento primordial de los indios, el ritual del areíto, el guatiao "o acuerdo amistoso entre individuos desconocidos" (2016, p. 20), y la visión de un recinto sagrado que los indios designaban con el nombre de Coaybay. Incluso podría argumentarse que, a medida que avanza el relato, el personaje va asimilando y ensanchando su imaginación según los mitos y las creencias de los indios. La diégesis subjetiva parece ir transformando su conciencia y sus creencias. El malogrado orate alimenta su relato con vivencias y acciones con características propias de lo real maravilloso, pues reconoce que los caciques taínos tenían cópulas con las opias muertas que habitan en los guayabales o el hecho de que los "espíritus taínos hablaron en lengua castellana”. (2016, p. 57)

El narrador, Nathaniel, según afirma el texto, era magrebí. Este aspecto aparentemente externo y contextual jugará un rol importante en la historia, ya que mientras escribe sus memorias en el convento de los jerónimos, Nathaniel, en su búsqueda de paz existencial, abrazará el ideal religioso de su tío judío Luis de Torres, quien defendía en carne viva la fusión de las ideas judaicas (Dios judío) con las ideas cristianas basadas en la doctrina de Cristo.
Sus superiores religiosos no simpatizaban con estas ideas, por lo que es declarado hereje y un poseído del diablo. Es, por ello, que termina en la hoguera.

Las ideas del fusionismo eran comunes en el siglo $\mathrm{xv}$, solo que eran clandestinas y sospechosas, aunque muchos adoptaron el catolicismo con tal de salvar su pellejo, pero en su intimidad seguían los preceptos de Yavé, el dios de los judíos, aunque "se quedan sufriendo el santoral, la misa y las confesiones obligatorias, lo mismo que las asechanzas de los delatores al servicio de Santo Tribunal de la Inquisición, el que ahora alcanzaba un poder que no tenía desde muchos años atrás" (2016, p. 135).

En definitiva, la novela tiene el tono de una larga epístola; carece de diálogos y las descripciones son muy opacas. El novelista ha querido mezclar en la estructura de la narración las sensaciones subjetivas del narrador testigo y la perspectiva omnisciente que se ramifica y se fragmenta en diversos comentarios y acotaciones al margen de la historia inicial. E, incluso, a partir de la página $164 \mathrm{el}$ relato adquiere un tono menos subjetivo y, por lo tanto, más exteriorizante (cuasi-policial); de modo que se yuxtaponen textos de los archivos de Indias que son firmados por un tal Genaro. El propósito de este intercambio anónimo de archivos e informaciones es la necesidad que tiene alguien, no sabemos quién, de conocer la verdadera historia de Nathaniel y las andanzas de su escabroso tío. La construcción narrativa y la intercalación de los fragmentos sugieren que la novela en cuestión es escrita por Pedro Mártir de Anglería; estamos pues ante datos escamoteados, ante personajes farsantes, traidores y cínicos, que se niegan a ser transparentes, como la misma india Jariquena que, una vez viaja (ya convertida en condesa) como esposa del conde Villavicencio, no reconoce al desgraciado Nathaniel.

Con esta novela, el escritor Veloz Maggiolo no solo muestra el escenario de la confrontación crucial de 
dos culturas diferentes (la indígena y la española), sino que aporta un nuevo ladrillo a la edificación plena de la nueva novela histórica en América, pues la imaginación simbólica es el mejor instrumento para conocer el pasado y los avatares de la condición humana y sus arduas luchas políticas, sociales y culturales. El texto es un catalejo que nos acerca a un pasado inmerecidamente olvidado.

\section{Referencias}

Di Pietro, G. (2010). La novela bíblica y el fin de la era. San Juan, PR: Editorial Unicornio.

Fonerín, M. A. (2016). "La novela bíblica dominicana”. En Hoy (Areíto). Recuperado de http://hoy. com.do/claves-para-leer-las-novelas-biblicas/
Veloz Maggiolo, M. (2017). La Navidad: memorias de naufragio. Madrid: Altera Ediciones.

\section{Datos de filiación}

Fari Rosario. Es candidato a doctor en Estudios del Español: Lingüística y Literatura por la Pontificia Universidad Católica Madre y Maestra (PUCMM); maestría en Lingüística Aplicada a la Enseñanza del Español por Universidad Autónoma de Santo Domingo (UASD); licenciatura en Filosofía por la Pontificia Universidad Católica Madre y Maestra (PUCMM).

Líneas de investigación:

La narrativa caribeńa y lo real maravilloso en Veloz Maggiolo y Alejo Carpentier. La metáfora y sus alcances lingüísticos y científicos.

Correo electrónico: ramón.rosario@intec.edu.do 